\title{
PEDAGOGIA, EDUCAÇÃO E PESSOA NA OBRA DE WILHELM DILTHEY: UM DIÁLOGO POSSÍVEL COM A ÁREA DA SAÚDE
}

\author{
Carlos Roberto FERNANDEs*
}

Denise Consuelo MOSER**

\begin{abstract}
*Enfermeiro, Mestre e Doutorando em Enfermagem, Professor na Universidade Federal do Espírito Santo, Departamento de Ciências da Saúde do Centro Universitário Norte do Espírito Santo, São Mateus - ES. E-mail: crfernandes-enf1@hotmail.com

**Enfermeira, Mestre e Doutoranda em Educação, Professora na Universidade Federal da Fronteira Sul, Curso de Enfermagem - Campus Chapecó - SC. E-mail: denise.moser@uffs.br
\end{abstract}

Recebido em: 25/10/2013 - Aprovado em: 1712/2013 - Disponibilizado em: 15/01/2014

\begin{abstract}
RESUMO - Introdução: Os debates pedagógicos do século XX refletem extensivos estudos realizados na Alemanha por Wilhelm Guillermo Dilthey e Friedrich Nietzsche e, na França por Georges Sorel e Henri Bergson. Ao militar no campo da Educação, percebe-se certo desconhecimento no Brasil da Filosofia e Pedagogia de Dilthey. Objetivo: explicitar as concepções de Pedagogia, de Educação e de Pessoa nas obras de Wilhelm Guillermo Dilthey. Método: Pesquisa bibliográfica de abordagem nomotética (na classificação de Wilhelm Windelband), de caráter analítico. Material: Fundamentos de um Sistema de Pedagogia e História da Pedagogia, ambos de autoria de Wilhelm Dilthey. Resultados: Postulados universais da Pedagogia condicionamse historicamente pelo ethos nacional, pelo ideal de sociedade, de vida, de formação de um determinado povo num determinado momento histórico; considerando-se que toda pessoa é histórica, toda verdadeira Filosofia desemboca na Pedagogia. Conclusão: Necessário desatar os ferrolhos da educação e da pedagogia, sem esquecer que o mundo histórico formado de pessoas é indissociavelmente antropológico-psicológico-histórico e no qual cada sociedade deve decidir qual é o seu ideal de sociedade, de pessoa, de nação - o que se traduz num ideal de educação formativa de pessoas para aquela sociedade e nação que se quer construir.
\end{abstract}

Palavras-Chave: Educação. Pedagogia. Enfermagem. Saúde.

\section{PEDAGOGY, EDUCATION AND PERSON IN WORK OF WILHELM DILTHEY: A DIALOGUE WITH THE POSSIBLE HEALTH.}

\begin{abstract}
Introduction: The pedagogical debates of the twentieth century reflect extensive studies conducted in Germany by Wilhelm Dilthey and Guillermo Friedrich Nietzsche, and in France by Georges Sorel and Henri Bergson. The military in the field of education, we find a certain lack in Brazil the philosophy and pedagogy of Dilthey. Objective: To explain the concepts of Pedagogy, Education and Individual in the works of Wilhelm Dilthey Guillermo. Method: Literature search for nomothetic approach (in classification W. Windelband). Material: Foundations of a System of Pedagogy and History of Pedagogy, both authored by Wilhelm Dilthey. Results: Postulates universal pedagogy is historically conditioned by national ethos, the ideal of society, of life, of training a particular people in a particular historical moment, considering that every person is historic, all true philosophy leads in Pedagogia. Conclusion: Need to loose the bolts of education and pedagogy, without forgetting that the historical world of people is inextricably formed anthropological psychological - historical and in which each society must decide which is your ideal society, person , nation which translates into an ideal educational training people for that society and nation that wants to build. Keywords: Education. Pedagogy. Nursing. Health.
\end{abstract}




\section{PEDAGOGÍA, EDUCACIÓN Y PERSONA EN LA OBRA DE WILHELM DILTHEY: UN POSIBLE DIÁLOGO CON LA SALUD.}

RESUMEN - Introducción: Los debates pedagógicos del siglo XX reflejan extensos estudios realizados en Alemania por Wilhelm Dilthey y Guillermo Friedrich Nietzsche, y en Francia por Georges Sorel y Henri Bergson. Los militares en el campo de la educación, es evidente algún malentendido en Brasil la filosofía y pedagogía de Dilthey. Objetivo: explicar los conceptos de la Pedagogía, Educación e individual en las obras de Wilhelm Dilthey Guillermo. Método: Búsqueda bibliográfica para la aproximación nomotética (en la clasificación de Wilhelm Windelband). Material: bases de un sistema de Pedagogía e Historia de la Pedagogía, tanto escrito por Wilhelm Dilthey. Resultados: Postulados pedagogía universal está históricamente condicionado por el espíritu nacional, el ideal de la sociedad, de la vida, de la formación de un pueblo en particular en un momento histórico determinado, teniendo en cuenta que cada persona es histórico, toda verdadera filosofía conduce en Pedagogía. Conclusión: Es necesario soltar los tornillos de la educación y la pedagogía, sin olvidar el mundo histórico de las personas está inextricablemente forma antropológico -psicológico - histórico y en el que cada sociedad debe decidir cuál es su ideal de sociedad, persona, nación - la que representa una formación de personas educativos ideales para que la sociedad y la nación que se quiere construir. Palabras clave: la educación. Pedagogía. Enfermería. Salud

\section{Introdução}

O debate pedagógico do século XX é o reflexo direto das ideias e dos modelos pedagógicos de alguns filósofos e pensadores e é possível destacar, na Alemanha, o pensamento com Wilhelm Guillermo Dilthey (1833 - 1911) e Friedrich Nietzsche (1844 - 1900) e, na França, Georges Sorel (1847 - 1922) e Henri Bergson (1859 - 1941): desses gigantes do pensamento pedagógico europeu, deter-se-á em Dilthey considerando-se o quase absoluto desconhecimento na área da saúde em geral e da Enfermagem, em particular sobre os seus trabalhos no campo da Pedagogia e da Educação.

As diferentes perspectivas reflexivas, críticas e pós-críticas da educação, não foram capazes de mobilizar os estudos e as pesquisas na saúde, de forma significativa. (NIETSCHE, 1998). Ao transitar nos referenciais teóricos, questiona-se sobre a fragilidade e a quase inexistente compreensão dos aspectos educacionais no campo da saúde e na relação de imersão e apropriação dos grandes pensadores.

$\mathrm{Na}$ busca de diferentes compreensões pedagógicas, nas quais coabitam saúde e educação, o itinerário é sair de um lugar, pois, quem transita se lança ao movimento, não necessariamente à busca de um ponto de chegada, fixo e certo, mas se dispõe aos riscos do que pode encontrar pelo caminho e em alguma medida, permite uma abertura para o que se pode encontrar.

Nesse percurso ainda se constata no Brasil desconhecimentos sobre a Filosofia, a Hermenêutica, a Psicologia e a Pedagogia de Dilthey.

Os textos de História da Filosofia e de História da Pedagogia fazem menções genéricas sobre seu pensamento como historista e estudioso do mundo da vida, mas sem maiores aprofundamentos. (SILVA, 2012, p.329)

$$
\text { Guillermo Dilthey é o teórico }
$$

central da Escola Histórica Alemã e o 
fundador da autonomia lógica, epistemológica e metodológica das Ciências do Espírito, hoje denominadas Ciências Humanas e Sociais; no âmbito da Escola Histórica Alemã, o Historismo é a revolução cultural oposta ao Iluminismo e ao Positivismo. $\mathrm{O}$ conhecimento mais aprofundado do pensamento de Dilthey pode levar à redescoberta de propostas e aberturas para o significado das Ciências do Espírito no contexto hegemônico das Ciências da Natureza.

A obra de Dilthey, hoje composta de 26 volumes em língua alemã, abrange os campos da Epistemologia, da Metodologia, da Lógica, da Teoria do Conhecimento, da Filosofia Moral, da Ética, da Estética, da Filosofia das Ciências da Sociedade, da Teoria da Psicologia, da Biografia, da Crítica Literária, da Arte, da Teoria da Educação, da Pedagogia.

Mais especificamente no campo do ensino de Pedagogia, Dilthey (1949) elaborou e ministrou os seguintes cursos em forma de aulas, entre 1874 e 1894:

$1^{\circ}$ ) na Universidade de Breslau

-"História da Pedagogia com aplicação da Psicologia em sua elaboração sistemática", no verão de 1874;

-"História da Pedagogia e bases de seu sistema", no inverno de 1874-1875;

-"História da Instrução Pública da Prússia”, no inverno de 1878-1879.

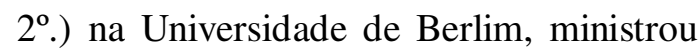
dois cursos em aulas com três horas semanais, entre 1884 e 1894, sobre "História e Sistema da Pedagogia" e “Aplicação da Psicologia à Pedagogia como complemento do curso de Psicologia". Com este último curso, Dilthey pode ser considerado o fundador da Psicopedagogia no campo das Ciências do Espírito.

O diálogo das Ciências da Saúde com as concepções de Dilthey sobre Pedagogia e Educação podem oxigenar o centralismo, ainda vigente, em modelos meramente instrutivos e normativos ancorados numa concepção questionável de educação em saúde, ainda fortemente positivista e fragmentada, sem efetivos resultados teórico-práticos tradutores de qualidade de vida das pessoas, não desacopladas da organização política das sociedades em que nascem, crescem, vivem e morrem.

Ao transitar pelo Paradigma Historista de Dilthey, nesse movimento de aproximações percebem-se as ambiguidades presentes entre a Educação e a Saúde, as quais continuam a buscar referências para refletir os fundamentos apresentados pelas Ciências Humanas e Sociais, muitas vezes abafadas pela preponderância das Ciências da Natureza. O pensamento de Dilthey aparece pouco explorado na busca das formulações teóricas necessárias para o momento atual 
- sobretudo pelo quase absoluto desconhecimento de que, Dilthey não é um referencial teórico, mas um paradigma para autonomia lógica, epistemológica e metodológica das Ciências Humanas e Sociais.

O tema da Pedagogia é colocado por Dilthey a partir do alicerce de sua Lógica Gnosiológica procedente de sua irretocável Teoria do Conhecimento. Hoje, está cada vez mais evidente que o pensamento pedagógico tem na definição do saber sua referência natural, e necessária em qualquer percurso pedagógico, assim como em qualquer esforço teórico de refletir filosoficamente sobre a educação. Não afeito a conclusões apressadas nem a sistemas fechados de pensamento, a questão da educação na obra de Dilthey.

Não se apresenta de forma completa, organizada ou acabada. É formado por propostas que, no seu dizer, se constituem em 'linhas de pesquisa' que conduzem a maiores aprofundamentos.

Os princípios e normas absolutas dão lugar ao valor da compreensão histórica do mundo humano, dos modelos culturais da contemporaneidade e dos tipos de vida que se tornam referências para a época atual, com validade universal. (SILVA, 2012, p.329)

Nesse sentido e no texto originalmente escrito em 1888, Sobre a Possibilidade de uma Ciência Pedagógica de Validade Universal, destaca-se a preocupação central de Dilthey (1954) sobre a Pedagogia: o erro de propor sistemas educativos universais e abstratos, desconsiderando os condicionamentos e as limitações intransponíveis do "ethos histórico de um povo". Talvez nisso resida os avanços teóricos e os retrocessos práticos das experiências educacionais brasileiras, importando teorias educacionais de outros povos sem que o próprio Estado Brasileiro tenha definido o seu ethos de sociedade, de nação, de povo. Eis porque se considera o diálogo com Dilthey fundamental tanto na área da Pedagogia em particular quanto na área da Saúde - diante das precariedades concretas seculares e vigentes desses setores no país.

\section{Objetivo}

- Explicitar as concepções de Pedagogia, de Educação e de Pessoa nas obras de Wilhelm Guillermo Dilthey.

\section{Método e Material}

Pesquisa bibliográfica, analíticoreflexiva, de abordagem nomotética (na classificação de Wilhelm Windelband), a partir das proposições e discussões sobre Pedagogia, na obra de Wilhelm Guillermo Dilthey.

Ao iniciar o labirinto metodológico, pensa-se em algumas questões a serem prudentemente partilhadas neste momento, levando-se à reflexão: e as possibilidades da pesquisa em educação? E porque a pesquisa documental para tratar a temática ora proposta? $\mathrm{Na}$ tentativa de refletir estas questões e transitar entre as diferentes perspectivas, cabe considerar a 
diversificação da pesquisa no campo da educação.

Veiga-Neto (2007) coloca holofotes em "novos e outros olhares na pesquisa em educação", já que este é um terreno incerto, desafiador e instigante, tendo em vista o envoltório de complexidade, transdiciplinaridade, transversalidades, presente no constituinte da pesquisa.

Antes de se debruçar nas questões apresentadas, destacam-se alguns aportes referentes aos estudos baseados em documentos e bibliografias, citado por Lüdke e André (2006), como material primordial, sejam eles revisão bibliográfica ou pesquisas historiográficas, pois é possível extrair deles informações e registros, organizados e interpretados segundo os objetivos da investigação proposta. A pesquisa documental depende dos documentos e estes precisam ser encontrados, extraídos e garimpados de prateleiras, arquivos e anexos, recebendo um tratamento que, orientado pelo problema proposto pela pesquisa, estabelece a sua montagem como num mosaico.

Minayo (2004) destaca ser esta uma técnica decisiva para a pesquisa em ciências sociais e humanas, a análise documental é indispensável porque a maior parte das fontes escritas - ou não - é quase sempre a base do trabalho de investigação e realizada a partir de documentos, contemporâneos ou retrospectivos, considerados cientificamente autênticos. A análise documental tem a intenção de evidenciar as categorias que emergem dos documentos e dos registros, buscando a representação condensada da informação, para consulta e armazenagem.

A análise documental constitui uma técnica importante na pesquisa nomotética (contemporaneamente batizada de qualitativa), seja complementando informações obtidas por outras técnicas, seja desvelando aspectos novos de um tema ou problema (LÜDKE, ANDRÉ, 2006).

\section{Material}

Duas obras de Guillermo Dilthey são utilizadas, resultantes da sua atividade docente em Pedagogia e traduzidas para a língua espanhola:

- Fundamentos de um Sistema de Pedagogia, traduzida por Lorenzo Luzuriaga e publicada no ano de 1949, em Buenos Aires.

- História da Pedagogia, igualmente traduzida por Lorenzo Luzuriaga e publicada no ano de 1957, em Buenos Aires.

\section{Resultados e Discussão}

1 - Postulado da Pedagogia de Dilthey

Os postulados e regras universais da Pedagogia, na concepção de Dilthey (1957), são sempre condicionados 
historicamente pelo ethos nacional e tem por teleologia:

-a "direção da atenção";

-o "cultivo multilateral das intuições";

-o "desenvolvimento e recheio da memória";

-a promoção da conexão da atenção, das intuições e da memória a partir de um determinado princípio historicamente condicionado.

De imediato, convém destacar a posição não psicológica nem psicologista do pensamento diltheyano: as faculdades psíquicas (e não psicológicas) da atenção, da memória e da intuição, enfim o eu e o pensamento são formações e desenvolvimentos historicamente condicionados. Noutros termos, a razão, a existência, a subjetividade humanas são históricas. (DILTHEY, 1986) Portanto, a abordagem psíquica de Dilthey é uma abordagem antropológico-histórica e não individualista/subjetivista.

O determinado princípio historicamente condicionado é para Dilthey (1957) o ethos nacional, o ideal de sociedade, o ideal de vida, enfim, o ideal de formação de um determinado povo num determinado momento histórico.

O ethos nacional, a não ser fundido e confundido com as experiências históricas dos absolutismos e dos imperialismos, parece ser o definidor político dos conteúdos da Pedagogia; talvez por isso, Mendes (1998), ao prefaciar a obra por ele mesmo coordenada, afirma que a Pedagogia oficial brasileira carece de conteúdos reduzindose a um amontoado ou "moinhos das leis" que, em última instância, destroi a própria experiência educacional. Ou seja, falta à Pedagogia brasileira, além do ethos nacional, a própria concepção política do que seja Pedagogia.

Aparentemente contraditório na mesma obra e noutro capítulo, Mendes (1998, p.83) afirma: a "pedagogia só tem especificidade própria como método de coordenar e aplicar saberes que a transcendem. Substancializar a pedagogia representa uma tentativa falaciosa e funesta”.

Quais seriam os saberes transcendentes à Pedagogia? O próprio Dumerval Trigueiro Mendes afirma que o mal da educação é ser ela ocupação de pedagogos mais que de cientistas sociais, filósofos, artistas, escritores e tantos outros profissionais; nesse caso, os saberes transcendentes à Pedagogia, esvaziada de conteúdos e definida como método da educação, estariam em todas essas possíveis áreas de conhecimento.

Duas concepções de mundo diferentes estão provavelmente em jogo: a historista diltheyana para a qual Pedagogia é ciência e filosofia política da Educação e para a qual Educação é teleológica atividade-meio; e a marxista de Mendes para a qual Pedagogia é método da 
Educação e Educação é teleológica atividade-fim.

Não seria da Didática o papel específico de método coordenador e aplicativo da Educação como atividademeio cuja ação didático-educacional determina-se pelos saberes da Pedagogia? Entretanto, esta é outra concepção de mundo, pois que, para Durmeval Trigueiro Mendes, Pedagogia sintetiza, coordena e aplica saberes de outras ciências e artes para a Educação.

Há, entretanto, que se atentar para o aparentemente contraditório da concepção de Mendes (1998) porque este parece não estar seguindo o pensamento pedagógico dos clássicos e nem o pensamento pedagógico dos séculos XVII e XVIII.

Dilthey (1949) esclarece que a ideia de um sistema pedagógico universal, negador das diferenças nacionais e das diferentes necessidades dos Estados, é criação dos séculos XVII e XVIII; para os clássicos mestres da Sofística e da Retórica, Pedagogia é a ciência que responde às necessidades da política grega, quanto o foi para o Estado romano e, por isso, os fins da educação clássica é a formação do homem político eficaz. Ou seja, Pedagogia é ciência política e filosófica formadora da pessoa humana cidadã.

No século XX, ao se ter esvaziado a Pedagogia de sua significação filosófica e política sinonimizando-a redenominando-a de Ciências da Educação, havia a necessidade de se inventar uma nova disciplina - a Filosofia da Educação e, para Durmeval Mendes, a Filosofia da Educação Brasileira.

Num parêntese explicitativo, convém lembrar algumas das chamadas Ciências da Educação: Antropologia da Educação, Sociologia da Educação, Psicologia da Educação, História da Educação, Filosofia da Educação, Teoria da Educação, História da Pedagogia ou História do Pensamento Pedagógico, Fundamentos da Educação, Política Educacional, Educação Ambiental, Ensino em Ciências. Essa seriação mais ou menos arbitrária traduz a obsessão por especialidades, à moda positivista, consequente à própria incapacidade de se abarcar o todo da realidade humano-sóciohistórica.

A Pedagogia foi sufocada em seu papel diretor da formação de pessoas, sociedades e Estados em nome de uma suposta (e não real) mundialização cultural mediada pela economia de mercado, a partir da segunda metade do século XX; essa mundialização cultural, deformadora ou destruidora da própria multidiversidade do ethos cultural das sociedades humanas e promotora da diluição da Pedagogia nas chamadas Ciências da Educação, é, possivelmente, a responsável direta do que se pode nomear de miséria da educação, 
sobretudo ainda vigente no Brasil deste início do século XXI.

\section{2 - Função da Pedagogia}

O que foi transliterado para o inventado subcampo da Filosofia da Educação, em verdade, é o campo da Pedagogia. E nisto, o pensamento diltheyano ainda é o pioneiro sem a obsessão do mundo do saber fragmentado por disciplinas (o saber em pedaços):

-“o florescimento e o fim de toda verdadeira Filosofia é a Pedagogia em seu mais amplo sentido qual seja o de formação do homem.” (DILTHEY, 1957, p.9)

Em sentido geral, Pedagogia significa, pois, a filosofia da formação da pessoa ou, se se quiser filosofia política da educação.

-à ciência da Pedagogia cabe a reflexão científica sobre a educação mesma. " (DILTHEY, 1957, p.9)

Em Dilthey, a ciência da Pedagogia não deve ser confundida com as pretensões positivistas de cientificidade no século XIX: condicionar a Pedagogia aos moldes lógico-metodológicos das ciências experimentais e erguer a malograda Pedagogia Experimental ou científicoexperimental fundada na Psicologia Experimental (científico-experimental ou Clínica). Por essa pretensão equivocada, iniciada no século XVII com Francis Bacon e Renè Descartes, a Pedagogia, no século XVIII, era uma doutrina teórica e geral de algumas faculdades psicológicas entre as quais estava o interesse (motivação), a atenção, a sensibilidade, a memória, o pensamento.

Esse foi o esforço teórico e epistemológico de Johann Friedrich Herbart (1776-1841) do qual procede a fundamental influência posterior sobre a concepção pedagógica liberal de John Dewey (1859 - 1952); Herbart intentou erguer uma Psicologia científicoexperimental (e, portanto, com métodos mecânico-matemáticos) sobre a qual também se edificaria a ciência filosófica e experimental da Pedagogia, responsável pela formação de uma nova pessoa por uma educação moral e por uma educação estética.

Contrariamente à Psicologia de Herbart, a Psicologia de Dilthey é analítica e descritiva, não dissociada da antropologia, da história e da filosofia nem existencialista nem fenomenológica, mas histórica ou histórico-historista e cujo método hermenêutico opõe-se ao mecânico-matemático para as Ciências do Espírito (Humanas e Sociais): esta Nova Psicologia, Histórica e Historista, serão à base da Pedagogia de Dilthey.

\section{3 - Pedagogia e Sistemas particulares}

Para evitar excessivas citações no texto, saibam o leitor e a leitora que todas as ideias aqui apresentadas procedem do 
pensamento diltheyano, consultáveis em suas duas obras pedagógicas constantes das referências bibliográficas.

A palavra pedagogia procede do grego paidagogia e é independente do vocábulo Paidéia.

Paidagogia significa acompanhamento e vigilância dos jovens realizados por seu condutor; pedagogo, procedente de paidagogos, era o nome dado a esse condutor.

Paidéia era o programa e o processo da Paidagogia; por isso, a melhor tradução para Paidéia é tanto a integral educação e formação dos jovens quanto formação cultural em geral do homem grego.

Paidéia significa educação, no sentido mais radical, integral e antigo de educação:

Os antigos estavam convencidos de que a educação e a cultura não constituem uma arte formal ou uma teoria abstrata, distintas da estrutura histórica objetiva da vida espiritual de uma nação; para eles, tais valores concretizavam-se na literatura, que é a expressão real de toda cultura superior. E é deste modo que devemos interpretar a definição do homem culto apresentada por Frínico. (JAEGER, 2003, p. 1)

Com tal concepção radical e integral de educação, pedagogo era o próprio condutor da formação daquele homem culto, de cultura superior.

Significação similar na atualidade ao pedagogo é dada à palavra e à ação do tutor ou facilitador da aprendizagem: a diferença entre a significação atual de tutor ou facilitador da aprendizagem da significação clássica de pedagogo está em que a este último cabia à função de mestre à qual se integravam as funções de condutor formativo da personalidade do aluno, de professor e de instrutor.

Ao longo do tempo houve, pois, uma redução ou precarização da ideia e das funções pedagógicas de tutor, de mestre, de professor, de instrutor: redutiva e possivelmente equivocada é a divisão atual da ideia e da ação do tutor centradas na aprendizagem e as de professor centradas no ensino.

O pedagogo, o mestre, o professor, o tutor seriam (e deveriam continuar sendo), clássica e não fragmentadamente, educadores.

Inúmeros e historicamente determinados são os conceitos de Pedagogia: sistemas pedagógicos foram pensados, montados e hegemonizados segundo a concepção de mundo de quem os pensou e montou, segundo modelos de Estado e sistemas de governos que os adotaram e os aplicaram; exatamente por essa característica historicamente determinada, a pretensão de validade universal desse ou daquele sistema pedagógico e suas variáveis estratégias compostas em sistemas educacionais é, no mínimo, uma concepção de "ciência atrasada".

A única validade desses ou daquele sistema pedagógico, incluindo-se nele os sistemas educacionais que o 
operacionalizam, é a validade histórica; talvez por isso, proliferam estudos sobre as histórias das ideias e das concepções pedagógicas, as histórias das ideias e das concepções educacionais, contrapostas à concepção metafísica de História da Pedagogia e História da Educação.

\section{4 - Concepção de educação}

Ao se conceber Pedagogia por ciência histórico-político-filosófica da Educação, Educação será o processo formativo da pessoa humana cujo objetivo é desenvolver os postulados, os objetivos e os conteúdos da Pedagogia mediante a criação das organizações educacionais para consecução do que a Organização para a Educação, Ciência e Cultura (UNESCO) defende como processo de aprender a aprender.

Interpretando desenvolvimento com Guillermo Dilthey como processo de diferenciação e aperfeiçoamento, o processo de aprender a aprender (que inclui, mas não se funda nem se limita ao chamado processo ensino-aprendizagem) envolve pelo menos sete atitudes e aprendizagens:

-criticoanálise dos processos educacionais; -problematização do processo ensinoaprendizagem;

-problematização da qualidade do ensinoaprendizagem; -consciência histórica; -consciência política;

-responsabilidade social;

-responsabilidade política.

No todo, as atitudes $\mathrm{e}$ as aprendizagens apresentadas e que na linguagem de Comenius seriam engenhos, remetem à missão, ao fim último e aos condicionantes da educação ou dos processos educacionais.

Para Dilthey (1949, p.14),

A missão da educação é o desenvolvimento do indivíduo por um sistema intencional de meios até o estado em que aquele indivíduo alcance autonomamente seu destino.

[... $\mathrm{O}$ ] fim último de toda educação é o desenvolvimento da afetividade, da vontade e de um mundo de ideias no indivíduo.

Esse fim último da educação expressa o conceito diltheyano de "ideal de formação", relacionado ao "ideal da sociedade".

O "ideal de formação" depende do “ideal de vida" de determinada geração de educadores, do "sistema de meios" realizador da educação e do "estado cultural" de uma determinada geração e de um determinado povo; consequentemente, a estrutura cultural de uma nação, formada pelo povo que a constitui, determina a educação.

O conceito de estrutura cultural de uma nação em Dilthey (1949, ps. 14 e 15) significa:

-sistema de representações finamente desenvolvido; -grupos de conceitos científicos;

-costumes; 
-constituição;

-fins práticos e ideais da vida;

-mundo de ideias no qual estão elaborados todos aqueles elementos e que se expressam na religião, na arte e na filosofia.

A missão suprema da educação, seguindo a mesma citação acima, é fazer com que o indivíduo integre esse mundo de ideias com todas as forças de seu espírito e que, na medida dessas forças, ocupe o lugar adequado naquele mundo tanto para sua satisfação quanto para a sua utilidade na totalidade desta cultura e de suas tarefas.

$\mathrm{Na}$ consecução daquela integração do indivíduo à estrutura cultural da nação, não se pode falar em Educação e Pedagogia, sem as atividades de ensino e de instrução, exercidas por educadores formais.

Ainda para Dilthey (1949), a profissão de educador exige duas competências (engenhos, na linguagem comeniana):

A) preparação pedagógica de toda a sua pessoa.

Fundada na psicologia histórica, não experimental, e na lógica histórica, a preparação pedagógica envolve conhecimento das experiências universais na história do ensino e da instrução, conhecimento das ideias sistemáticas e teorias pedagógicas antiga, clássica, moderna e contemporânea.
B) conhecimento científico da matéria pedagógica, educacional e didática a ser ensinada pelo educador.

$\mathrm{Na}$ concepção pedagógica diltheyana educar é a um só tempo, formar (bilden), ensinar e instruir.

Formar é toda atividade produtora de aperfeiçoamento dos processos numa pessoa. Formação é todo gênero de aperfeiçoamento daquela pessoa. (DILTHEY, 1949, p.52)

Relembrando: para o Historismo de Dilthey, lei de desenvolvimento significa diferenciação e aperfeiçoamento sendo que este último compõe-se da lei de formação.

Na concepção de Guillermo Dilthey educação é um sistema cultural de formação, historicamente determinado, desenvolvido mediante ensino e instrução e dirigido pela Pedagogia. Nesse sentido, os supostos saberes da Educação são saberes da Pedagogia objetivada na história da educação e na história dos sistemas pedagógicos ou das teorias, ideias e concepções educacionais dos vários sistemas de Pedagogia.

As duas competências do educador, destacadas por Dilthey, afirmam e antecipam o que somente no século $\mathrm{XX}$ será dito quanto à constituição do saber pedagógico, compaginado num "repertório de conhecimentos" inerentes ao ensino a que eu denomino de Arquitetura do Saber Pedagógico.

A integral preparação pedagógica da pessoa do educador e o conhecimento 
científico da matéria pedagógica, educacional e didática a ser ensinada pelo educador são as duas competências assinaladas por Dilthey e traduzem a Arquitetura do Saber Pedagógico.

\section{5 - Concepção de Pessoa}

Fundamental para a Pedagogia de Dilthey é a sua concepção de pessoa, nomeada por ele de unidade de vida ou unidade psicofísica de vida. (DILTHEY, 1986)

-“o homem, como fato precedente à história e à sociedade é uma ficção da explicação genética; o homem, objeto da sã ciência analítica, é o indivíduo - parte integrante da sociedade." (DILTHEY, 1986, p.64; DILTHEY, 1949, ps. 40-1)

-o homem individual, como ser isolado, é mera abstração: o parentesco de sangue, a convivência loca a cooperação no trabalho, na competência e na atividade comum, as múltiplas conexões produzidas pela consecução comum dos fins, as relações de poder no mando e na obediência, fazem do indivíduo membro da sociedade. (DILTHEY, 1954, p.179)

-O homem se nos apresenta como unidade de vida pela dupla perspectiva em que o concebemos: nexo de fatos espirituais até aonde alcança a percepção interna e um todo corporal por onde o captamos por meio dos sentidos. A expressão da unidade psicofísica de vida é o abarcamento dos fatos espirituais e dos fatos corporais em sua conexão. (DILTHEY, 1986, p.49)
-O indivíduo respira na família, na igreja, na vida científica, na coerência sócio-estatal; desde o princípio, vive em relações vitais das quais nada deverá isola-lo. Nesse processo, a educação somente poderá guiá-lo e formá-lo. (DILTHEY, 1973, p.165)

- os sujeitos são "unidades reais", expressam-se como "fatos"; "fatos na experiência íntima". São unidades de vida, "totalidades psicofísicas". (DILTHEY, 1986, p.61)

Por esta concepção historista ou histórica do indivíduo procede ao conceito de razão histórica: o pensamento, o eu, a consciência, a individualidade são históricas; subjetividade é historicidade. Essa historicidade é estrutura una indivisível, a natureza humana é historicidade e totalidade. Eis, em Dilthey, a indissociabilidade entre antropologiapsicologia-história para abarcar essa unidade de vida completa, íntegra, total, plena e não mutilada nem abstrata. (DILTHEY, 1986)

Uma Pedagogia e uma Educação fundadas naquela unidade de vida (que somos todos nós) é, a um só tempo, filosofia antropologia psicologia história: por isso, Dilthey afirma ser a Pedagogia a última palavra da Filosofia, a "meta prática mais alta a que pode conduzir a filosofia". (DILTHEY, 1954, p.333) Mais radicalmente: "a floração e fim de toda verdadeira filosofia é a pedagogia em seu mais amplo sentido de teoria da formação do homem.” (DILTHEY, 1954, p.9)

Estamos diante da formulação genuína da Pedagogia Política de Dilthey: e mais, a concepção histórica-social- 
pragmática (e não teórico-abstrataespeculativa) da Filosofia.

\section{6 - As concepções pedagógicas de} Dilthey para a área da saúde

$\mathrm{Na}$ tentativa de explicitar as perspectivas pedagógicas de Dilthey, no campo da saúde, Fernandes (2010), um estudioso da obra de Dilthey e da Enfermagem brasileira, destaca outras abordagens históricas relevantes que esclarecem as práticas e os modelos de Enfermagem no contexto das mudanças sociopolíticas brasileiras. Há estudos estruturais, com breves introduções históricas da Enfermagem brasileira, mantendo a concepção evolucionistasociológica da história, e análises estruturais diferenciadas de uma concepção marxiana. Exemplifica-se com um desses estudos onde o autor destaca o estudo de Lunardi (2004), para reafirmar as rupturas e continuidades na história da Enfermagem mediante o conceito foucaultiano de governabilidade do poder.

Para Fernandes (2010), um dos problemas centrais no campo da saúde e mais especificamente na Enfermagem é a raridade das escrituras sobre história da Enfermagem brasileira, antecedida por uma milenar história (não evolutiva) da arte de cuidado no território nacional totalmente povoado há mais de nove mil anos antes de Jesus, conforme o demonstra a Arqueologia Brasileira. (TENÓRIO,
2000) Toda essa milenar história do cuidado e do não cuidado não pode ser negligenciada pela Enfermagem Brasileira: os problemas de doença e de saúde, de cuidado e de não cuidado no Brasil não são contemporâneos nem modernos. E a partir de 1500, um ethos de não cuidado instalouse paulatina e agressivamente, cujas expressões continuam vigentes no século XXI naquilo que Ribeiro (2001) denomina de moinho e criatório de gentes $\mathrm{e}$ Fernandes (2007) nomeia de violência histórica fundada na gastação e moeção de corpos - expressas por ontocídio instrumentalizado por ecocídio, corpocídio, corpofagia.

Fernandes (2010) pontua que os esforços de se formar um contexto de estudos históricos dos processos de cuidado e dos processos de não cuidado ligam-se à busca de consolidação de um processo de cientifização da profissão Enfermagem: para isso, historiadores da arte de cuidado e da Enfermagem dialogam, mas não se referenciam na ciência histórica já constituída. Isso quer dizer que enfermeiros e enfermeiras não têm que fazer graduação e pós-graduação em história ou submeterem-se aos pareceres e paradigmas da ciência histórica constituída para historiar e historiografar a arte de cuidado e processos de não cuidado: essa arte é domínio da Enfermagem, em todas as suas dimensões históricas e aos historiadores e 
historiógrafos do cuidado cabe estruturá-la em campo epistêmico.

A dificuldade de estudos históricos da Arte de Cuidado no Brasil é pleonasticamente histórica: ao se confundir com a proliferação de cortes, fragmentos, reduções, partes e pedaços de histórias comete-se o mesmo erro de considerar o modelo herodotiano de história, baseado em meganarrativas de feitos heroicos ou de personalidades destacáveis no mundo econômico, político, religioso, artístico, dentre outros. Por outro lado, a análise hermenêutica de trajetórias e memórias de corpo pode parecer absurda àqueles pensadores para quem, por exemplo, defende que as ações de cuidado (leia-se igualmente ações de cuidado de Enfermagem) baseiam-se no conhecimento de sinais e sintomas de doenças conhecimento este, aliás, da Medicina.

No primeiro caso, faz-se microhistória dos fatos emergentes dos cortes, fragmentos, partes e pedaços, tendo-a por história universal: toda a obra de Hermenêutica de Guillermo Dilthey insurge-se em oposição a essa microhistória, composta por seriações de expressões da vivência, ou conforme defende Fernandes (2010), de memórias de corpo; no segundo caso, faz-se a redução dos fatos ao que, arbitrariamente, é mais ou menos valorizado ou legalizado, num determinado momento histórico, por essa ou aquela cultura, sociedade ou Estado: é o testemunho, por exemplo, dos livros de história do Brasil contando a versão histórica dos povos colonizadores e vencedores contra os povos colonizados e vencidos; no terceiro, acredita-se que a base fundamental do conhecimento da Enfermagem é biológica e a base fundamental da assistência é curativa, reduzindo-se a pessoa humana fragilizada e adoecida a um conjunto de sinais e sintomas cuja história é de doença, e não de vida ou expressão da vida histórica: as disciplinas antropologia da saúde e antropologia da doença, ambas nascentes da antropologia médica, tem buscado rever esse tipo equivocado de história de saúde e de história da doença.

A contribuição apresentada para aquela estruturação é a proposição do campo epistêmico Historística, subcampo especial da ciência do cuidado, cuja teleologia é desenvolver sistemático estudo e composição da história e historiografia da arte de cuidado no Brasil uma arte que antecede, inclui e ultrapassa a história da enfermagem brasileira; da mesma forma, os estudos da Historística, centrado nas memórias de cuidado, memórias de não cuidado e subsidiando o desenvolvimento de uma educação para o cuidado ou educação centrada no cuidado, distanciamse dos conceitos biomédicos de saúde, de doença e da prática médica de educação em saúde. (FERNANDES E NASCIMENTO, 2005) 


\section{Conclusão}

As concepções não universalizantes nem relativistas da Pedagogia de Dilthey fundam-se na necessidade pragmática e programática dos Estados, nações e sociedades de estabelecerem um ideal de formação (educacional) concreta e historicamente alicerçada na teleologia daqueles próprios Estados, nações e sociedades: uma teleologia não abstrata, nem individualista e nem especulativamente societária.

Com Dilthey, o mundo histórico formado (por e) de pessoas é indissociavelmente antropológicopsicológico-histórico e no qual cada sociedade deve decidir qual é o seu ideal

\section{REFERÊNCIAS}

1.Cambi F. História da Pedagogía. São

Paulo: Unesp. 1999

2.Dilthey W. Fundamentos de un sistema de Pedagogia. 3. ed. Buenos Aires: Losada. 1949

3. Teoria de la concepción del mundo. 2 ed. en español. México: Fondo de Cultura Económica. 1954

4. História de la pedagogía. 5. ed. Buenos Aires: Losada. 1957.

5.

Ética. Buenos Aires: nova. 1973

6. . Crítica de la razón

histórica. Barcelona: Península, 1986 7. Introdução às de pessoa e de nação - o que se traduz num ideal concreto de educação formativa de pessoas para aquela sociedade e nação que se quer construir. Somente assim, cada sociedade e nação constituirá o seu Sistema de Pedagogia, consecutor daqueles ideais cuja teleologia é formar, ensinar, instruir pessoas para uma sociedade. Esse processo exige consciência histórica, potencialmente capaz de superar os processos históricos de não cuidado com indivíduos, povos e nações e de estabelecer um novo ethos nacional.

fundamentação para o estudo da sociedade e da história, Rio de Janeiro: Forense Universitária, 2010

8.Fernandes CR, Nascimento ES. Historística: o campo dos fundamentos históricos da Ciência do Cuidado. Texto Contexto Enferm, 2005 out-dez; 14(4):5207

9.Fernandes CR. Violência moral na Enfermagem. Goiânia: AB, 2007

10. .Fundamentos do processo saúde-doença-cuidado. Rio de Janeiro: Águia Dourada, 2010

11.Jaeger W. Paidéia: a formação do homem grego. 4. ed., 2. tiragem. São Paulo: Martins Fontes. 2003

12.Lüdke M, André MEDA. Pesquisa em educação: abordagens qualitativas. São Paulo, EPU, 2006.

13.Lunardi V. História da Enfermagem: rupturas e continuidades. 2. ed. Pelotas: Ed. do autor, 2004 
14.Mendes DT. Filosofia da educação

brasileira. Rio de Janeiro: Civilização

Brasileira. 1998

15.Minayo MCS. Pesquisa social: teoria, método e criatividade. Petrópolis: Vozes, 2004.

16.Nietsche EA. As Teorias da Educação e o ensino da Enfermagem no Brasil. In:

Saupe, organizadora. Educação em

Enfermagem. Florianópolis: UFSC. 1998;

119-161

17.Ribeiro D. O Povo brasileiro: a

formação e o sentido do Brasil. 2. ed. 18.

reimpr. São Paulo: Companhia das Letras, 2001

18. Silva, JI. Filosofia e Educação: Textos selecionados. Organização e Introdução

Maria Nazaré de Camargo Pacheco Amaral;Tradução de Alfred Josef Keller e Maria Nazaré de Camargo Pacheco Amaral. In: Educação e Filosofia, Uberlândia, 2012 jan./jun.; 26(51): 327-36

19.Tenorio MC, organizadora. PréHistória da Terra Brasilis. Rio de Janeiro: UFRJ, 2000

20.Veiga-Netto A. Olhares... In: Costa MV (Org.). Caminhos investigativos I: novos olhares na pesquisa em educação. 3. ed., Rio de Janeiro: Lamparina Editora, 2007; 23-38. 